\title{
A STUDY OF EFFECT PROCESS PARAMETERS ON TENSILE STRENGTH
}

\author{
G. C. Jadhav \\ Research Scholar, Department of Mechanical Engineering, Government College of \\ Engineering, Amravati, India \\ Dr. R. S. Dalu \\ Professor and I/C Principal, Department of Mechanical Engineering, Government College of \\ Engineering, Sant Gadge Baba Amravati University, Amravati, Maharashtra, India.
}

\begin{abstract}
Friction stir welding (FSW) is a comparatively innovative solids-state joining process. This joining mechanism is very energy efficient, environment friendly and multitalented. The aim of this paper is improvement an affiliation between in the welding parameters and mechanical properties of the AA6061T-6 type of aluminum alloy using the friction stir welding mechanism. The effects of the various processing parameters they are, tool rotational speed, traverse speed, axial force and geometry play tool they are play an important role on the quality of welded joining. The FSW joints mechanism have advanced tensile strength to the heaviness ratio. The present work of this paper is done to think about the impact of the contribution parameters on the tensile strength. The tensile welding parameters mainly influenced by the following variables they are weld speed, feed, and tilt angle. The parameters are taking these of the examiner attributes they are the attributes are rotational speed, weld speed, axial force, shoulder diameter and tilt angle. From this examination it is found that the square tool pin profile producers are mechanically sound defect free welds compare to the tool to pin effects.
\end{abstract}

Key words: Friction stir welding, 6061 aluminium alloy, tool in profile, parameters, tensile properties.

Cite this Article: G. C. Jadhav and Dr. R. S. Dalu, A Study of Effect Process Parameters on Tensile Strength, International Journal of Advanced Research in Engineering and Technology, 10(2), 2019, pp 482-490.

http://iaeme.com/Home/issue/IJARET?Volume=10\&Issue $=2$

\section{INTRODUCTION}

In the welding institute (TWI) of United Kingdom in 1991 developed an innovative solid-state joining process and it was the first and foremost initiated to aluminum alloys. The aluminum alloys are normally classified as non-weld-able and the reason of the disadvantaged solidification microstructure along with the porosity in the fusion zone. And also, the losses in the mechanical attributes are dissimilarity to the base material in very significant. These factors compose to joining of these aluminum alloys by the traditional welding processes are 
unappealing. In the resistance welding are sometimes used aluminum alloys, but it is very expensive in exterior preparation. And it will create a major problem in surface oxide.

In the FSW procedure utilizing the revolution device is utilized to do the welding procedure. In the pivot device contain the undersized stick (test) undersized the unrivaled shoulder. The device contain three essential capacities they are known as work piece warming, material development for joint generation and the concealment to the hot metal underneath the device bear, The FSW instrument containing the joining plates and the revolution bear device powers to the warmth and it recently created from the grinding flanked by the welding apparatus (They together with the shoulder and the test) and they utilize the welded material. The welded material is form into the gentler at the temperature less than the softening point. As far as possible to the diminish material and underneath to the shoulder and they prompt the further advancement of material from the front of the stick and to the back of the stick through to the device revolution and the change development. It contrasted with the combination welding strategies, and it is unsurprising that this system will naturally and makes a weld with a practically identical measure of suffering pressure and disfigurement and no softening of material will happen at certain stages in the welding. The aluminum amalgams have a broad assortment of the properties. Amidst all aluminum amalgams, AA 6061 compound acting a most basic job in the airplane business wherein silicon $(0.3-1.5 \mathrm{w} \%, \mathrm{Si}, \mathrm{Mg})$ and magnesium are the preeminent alloying properties [6-7]. It contrasted with other aluminum compounds like $[1,2$, and 5]. This instrument constantly utilized in the aviation applications as a result of its great formability, welds capacity, matches failure, erosion opposition and great quality. The grating blend welding is likewise viewed as the huge measure of the earth-shattering advancement in the metal participates till ten years. They have no utilization of the twist gas or vacillation in the contact blend welding in the welding procedure and are the conservational vitality effectiveness and adaptability or it is a green innovation. The metal joining process does not permit any utilization of channel metals and that much of the time. Whichever aluminum composite can be joined with no worry for the similarity of artful culmination, this is the issue of combination welding. There is less utilization of the twist gas or variance and they association of any utilization in the metal channel I FSW, and the properties of the metal joining that are improved contrast with the parent metal [4]. The contact blend welding utilized distinctive kinds of metal joining. They are $\mathrm{T}$ butt joints, lap joints, filet and pipes. In these joining procedures each join have diverse thickness and distinctive profile. In the foundation of FSW system was produced for Al-combinations. Furthermore, the gainful blending apparatuses and they are vital for metal welding. In this circumstance the titanium and steel compounds are used as a metal framework of composite materials and those material are have taking off liquefying temperatures. The instrument material, apparatus pivot, weld speed along the joint line, device plan and descending power are the vital parameters chiefly consider in this procedure. Making the frictional warming loosens up the material underneath the mechanical assembly. The casual material streams in the blueprint of the mechanical assembly through broad plastic bending and it is consolidated at the back of the gadget to shape a solid-state steady joint. The attempt has been developed to understand the consequence of equipment stick profiles and rotational speed on FSP zone progression. The relationship between the FSP zone progression and moldable properties of disintegration mix welded AA2219 aluminum amalgam joints was dismembered [8]. He clear up the effects of rotational speed of the contraption, tilt purpose of equipment, similarly as turning course of the gadget on the macrostructure, microstructure, and mechanical characteristics of Al 5754 butt joints [9]. The impact of improvement imperatives in FSW on the weld metals was resolved and determined. The Vickers strength, malleable power and radiography are estimated for investigation by means of changing the speed of hardware, apparatus feed and at weld the profundity of infiltration is keeping up at steady [10]. According to the requirements and highlights the Taguchi test 
structure and choice of symmetrical cluster was finished [11]. The fundamental capacity of the non-consumable rotating instrument stick is to mix the plasticized metal and it has a decent joint. Stick profile is a critical position in material stream and furthermore the speed of welding is controls by the FSW procedure $[13,14]$. Stick profiles with smooth articulation (square and triangular) are connected with capriciousness. This capricious conduct empowers the incompressible material to circumvent the stick profile [15]. The instrument of onion ring improvement in the erosion mix welds of aluminum composites and furthermore he found that the dimension of material combination and entomb dispersion, the thickness of disfigured aluminum lamellae, just as material stream designs exceedingly dependent on the geometry of the apparatus, welding meteorology, successively dependent on the hub constrain the material stream pressure happens [16]. Analyze the effect of hardware stick profile (straight round and hollow and square) on the advancement of grinding blend preparing zone in a singular and back to back double-sided rubbing mix weld in AA6061 [17].

Results show solid connection and vigorous examination between the weldment quality and procedure parameters and determination of ideal procedure parameters for effective weld. The welding parameters are the key craft of erosion blend welding process. In the present examination, the impact of parameters on mechanical properties of grating mix welded aluminum amalgam AA6061T-6 was contemplated. In all trials instrument stick measurement and its length kept steady.

\section{MATERIALS \& EXPERIMENTAL PROCEDURES}

\subsection{Materials}

The aluminum AA6061 compound with the measure of $100 \mathrm{~mm}$ long and $82 \mathrm{~mm}$ in width and the $6.3 \mathrm{~mm}$ in thickness these materials are utilized in the examination show in Figure 1.
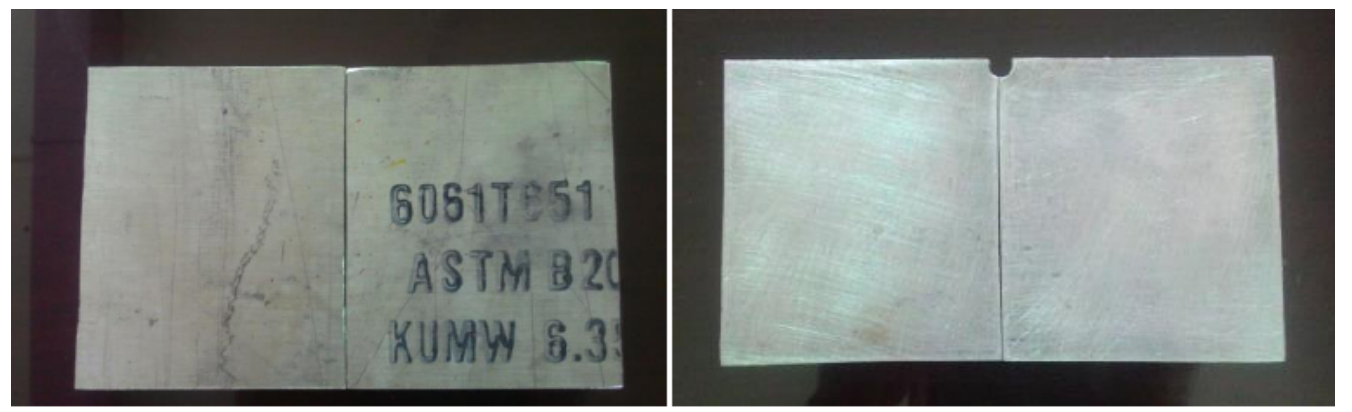

Figure 1. Aluminum Alloy plates

The aluminum AA6061T-6 compound is a standout amongst the most broadly utilized amalgam in the 6000 arrangement. This aluminum composite is a standout amongst the most multitalented temperature compound. The aluminum combination is the most acclaimed for the medium to high power prerequisites and it has great heartiness singularity. It is a remarkable rot protection from ocean water and the climatic conditions. The joining materials are broadly utilized in air ship businesses, car parts, speed train, yatch development and so on. The accompanying figure demonstrates the work piece material utilized for FSW process.

\subsection{Welding Tool}

For this experiment the welding tool is designed. The D2 steel is used to design the welding tool. The different kinds of tools are used to the friction stir welding (FSW) joints. They have the probe shapes like cylinder and square that are shown in the Figure 2 with their dimensions in Figure 3. 

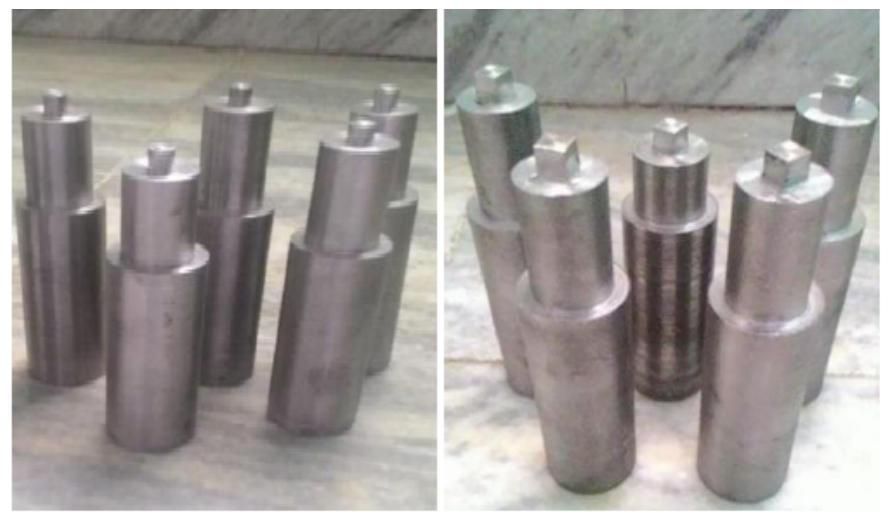

Figure 2. Different FSW tools

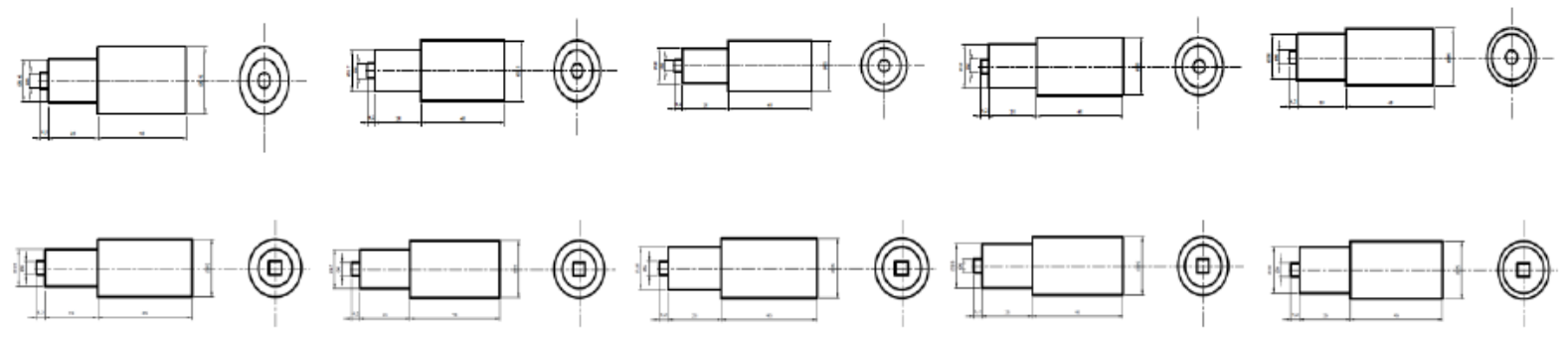

Figure 3. Straight cylindrical and square FSW tools

\subsection{Frictions stir welding on universal milling machine with vertical attachment.}

To take the process of FSW in universal milling machine (Model BFU-5) was used to metal joining. In this process we primarily use fifty pieces of AA6061 material are organized up for the purpose of friction stir welding. The total number of experimentations is given by the Taguchi optimum design technique. The vertical attachment is that shown in the Figure 4.

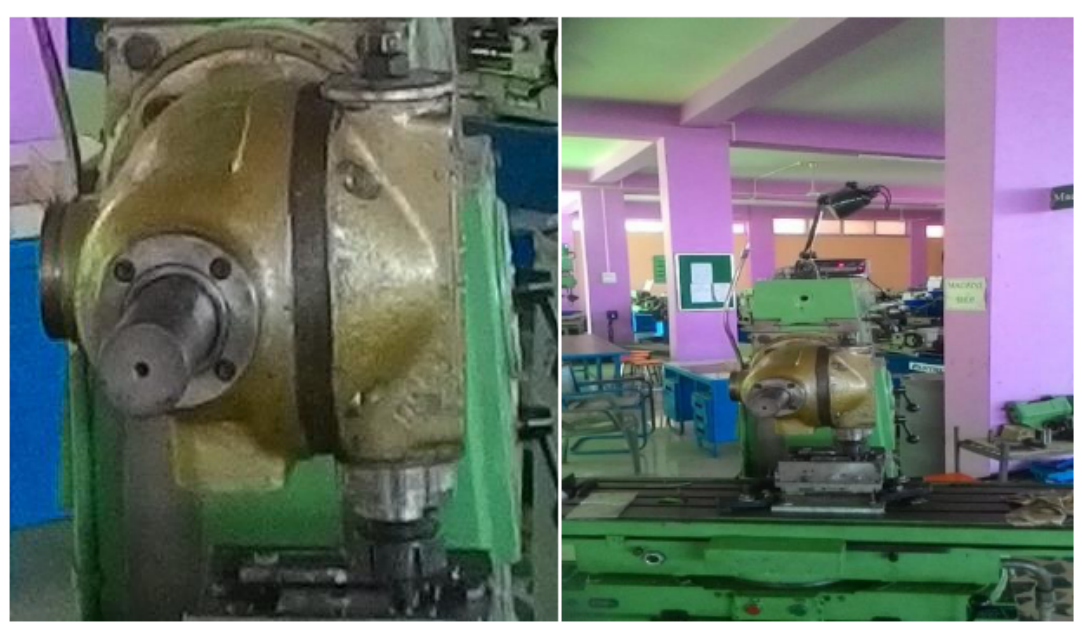

Figure 4. Vertical attachment and milling machine

\subsection{Working level of process parameters}

The five procedure parameters are having been looked over the writing overview, the detail of the realistic all-inclusive processing machine and the stick instrument width and the length is often keep to steady for the investigations. The three-grinding mix welding (FSW) instrument profiles have been considered for the metal joining. The metal joining tests are structured by 
utilizing the business programming MINITAB 17. This system enables the quantity of information to decide as the variables that for the most part influence the item quality with least number of experimentations along these lines sparing time and assets. The principle favorable circumstances of this technique is the sparing of leading of analyses and furthermore sparing exploratory time, diminish the expense of the procedure and decide the critical factor rapidly. Welding parameters are utilized to try the instrument speed, table feed and hub constrain bear distance across and tilt point.

\subsection{Taguchi experimental design technique}

In this process as use the number of the parameters and it increases it is to very difficult and its time consuming to correlate the parameters to run the experiments. So go for Minitab 17 software and it gives $\mathrm{L}_{25}$ orthogonal array design. Taguchi orthogonal array design is as shown below in table 1 .

Table 1 Taguchi orthogonal array design

\begin{tabular}{|c|c|c|c|c|c|}
\hline S.N. & Speed(rpm) & Feed(mm/min $)$ & Axial Force $(\mathrm{kN})$ & $\begin{array}{l}\text { Shoulder } \\
\text { dia.(mm) }\end{array}$ & Tilt angle(degree) \\
\hline 1 & 500 & 14 & 5 & 16 & 0 \\
\hline 2 & 500 & 20 & 6 & 17 & 1 \\
\hline 3 & 500 & 28 & 7 & 18 & 1.5 \\
\hline 4 & 500 & 40 & 8 & 19 & 2 \\
\hline 5 & 500 & 56 & 9 & 20 & 3 \\
\hline 6 & 710 & 14 & 6 & 19 & 1.5 \\
\hline 7 & 710 & 20 & 7 & 20 & 2 \\
\hline 8 & 710 & 28 & 8 & 16 & 3 \\
\hline 9 & 710 & 40 & 9 & 17 & 0 \\
\hline 10 & 710 & 56 & 5 & 18 & 1 \\
\hline 11 & 1000 & 14 & 7 & 17 & 3 \\
\hline 12 & 1000 & 20 & 8 & 18 & 0 \\
\hline 13 & 1000 & 28 & 9 & 19 & 1 \\
\hline 14 & 1000 & 40 & 5 & 20 & 1.5 \\
\hline
\end{tabular}


G.C.Jadhav and Dr.R.S.Dalu

\begin{tabular}{|c|c|c|c|c|c|}
\hline 15 & 1000 & 56 & 6 & 16 & 2 \\
\hline 16 & 1400 & 14 & 6 & 20 & 1 \\
\hline 17 & 1400 & 20 & 8 & 16 & 1.5 \\
\hline 18 & 1400 & 28 & 9 & 17 & 2 \\
\hline 19 & 1400 & 40 & 5 & 18 & 3 \\
\hline 20 & 1400 & 56 & 6 & 19 & 0 \\
\hline 21 & 2000 & 14 & 5 & 18 & 2 \\
\hline 22 & 2000 & 20 & 1 & 19 & 3 \\
\hline 23 & 2000 & 28 & 2 & 20 & 0 \\
\hline 24 & 2000 & 40 & 3 & 16 & 1 \\
\hline 25 & 2000 & 56 & 4 & 17 & 1.5 \\
\hline
\end{tabular}

\subsection{Methods}

2.7.1 Fabrication of FSW samples on milling machine as per Taguchi Design for cylindrical profile as shown in figure 5.

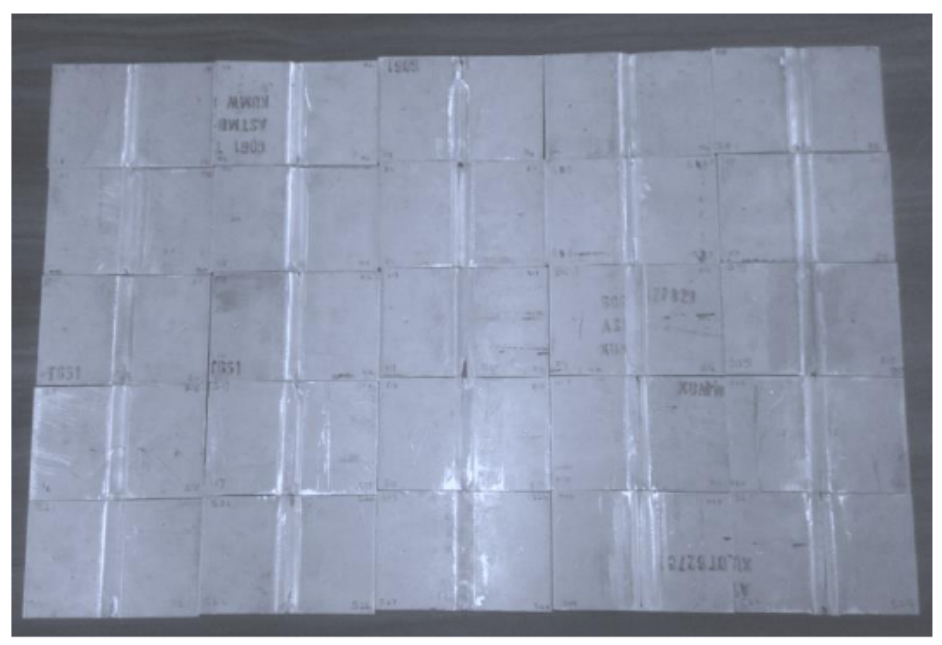

Figure 5. FSW samples of cylindrical profile 


\subsubsection{Preparation of samples for tensile test}
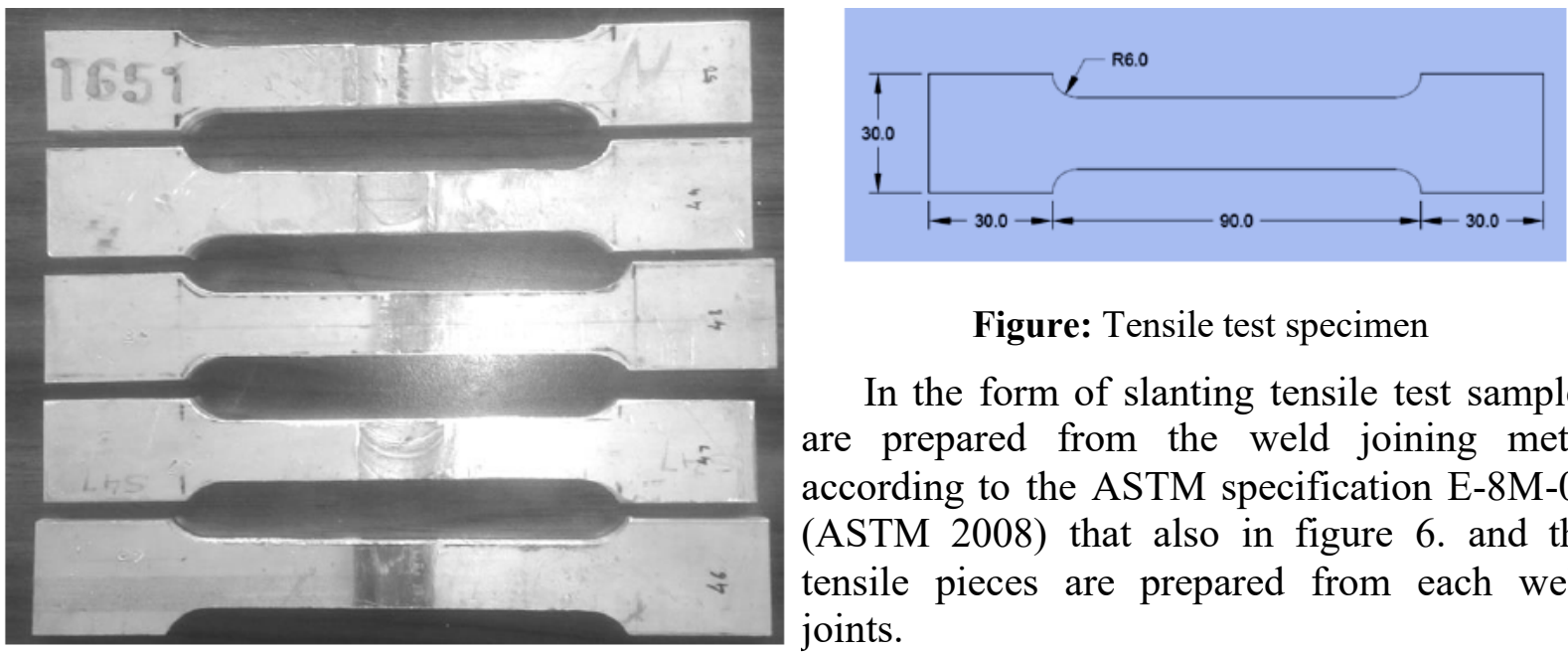

Figure: Tensile test specimen

In the form of slanting tensile test samples are prepared from the weld joining metal according to the ASTM specification E-8M-08 (ASTM 2008) that also in figure 6. and the tensile pieces are prepared from each weld joints.

Figure 6 Tensile samples of FSW welds

\section{RESULTS AND DISCUSSION}

For the cylindrical profile ideal elasticity acquired for sample no S11 at parameters speed 1000 $\mathrm{rpm}$, feed $14 \mathrm{~mm} / \mathrm{min}$, pivotal power $7 \mathrm{kN}$, bear measurement $17 \mathrm{~mm}$ and tilt point $3^{0}$ and for square profile is at parameters speed $710 \mathrm{rpm}$, feed $20 \mathrm{~mm} / \mathrm{min}$, hub drive $7 \mathrm{kN}$, bear width 20 $\mathrm{mm}$ and tilt edge $2^{0}$.Upto certain breaking point rigidity increments as the speed builds at that point diminishes. Expanding the speed, the warmth input increments amid welding and mellowing the weld piece diminishes with expanded in feed rate. As the feed rate increments elasticity diminishes. Additionally, higher shoulder distance across expands heat input and relaxes the material close to the contacts of hardware or more surface of material. Greater than one tilt point is requiring for higher elasticity. Medium axial power is required to get ideal rigidity. Tensile strength for cylindrical and square profile is shown in table 2 and table 3 respectively. The graph shows tensile strength versus speed for cylindrical and square FSW tool profile in figure 7.

Table 2: Tensile strength with sample number in $\mathrm{kN} / \mathrm{mm}^{2}$

\begin{tabular}{|c|c|c|c|c|c|c|c|c|c|c|c|c|}
\hline $\mathrm{S}_{1}$ & $\mathrm{~S}_{2}$ & $\mathrm{~S}_{3}$ & $\mathrm{~S}_{4}$ & $\mathrm{~S}_{5}$ & $\mathrm{~S}_{6}$ & $\mathrm{~S}_{7}$ & $\mathrm{~S}_{8}$ & $\mathrm{~S}_{9}$ & $\mathrm{~S}_{10}$ & $\mathrm{~S}_{11}$ & $\mathrm{~S}_{12}$ & $\mathrm{~S}_{13}$ \\
\hline 0.185 & 0.193 & 0.186 & 0.162 & 0.152 & 0.221 & 0.218 & 0.199 & 0.077 & 0.106 & 0.234 & 0.126 & 0.132 \\
\hline $\mathrm{S}_{14}$ & $\mathrm{~S}_{15}$ & $\mathrm{~S}_{16}$ & $\mathrm{~S}_{17}$ & $\mathrm{~S}_{18}$ & $\mathrm{~S}_{19}$ & $\mathrm{~S}_{20}$ & $\mathrm{~S}_{21}$ & $\mathrm{~S}_{22}$ & $\mathrm{~S}_{23}$ & $\mathrm{~S}_{24}$ & $\mathrm{~S}_{25}$ & -- \\
\hline 0.151 & 0.103 & 0.171 & 0.140 & 0.169 & 0.165 & 0.035 & 0.162 & 0.213 & 0.098 & 0.072 & 0.042 & -- \\
\hline
\end{tabular}




\section{G.C.Jadhav and Dr.R.S.Dalu}

Table 3: Tensile strength with sample number in $\mathrm{kN} / \mathrm{mm}^{2}$

\begin{tabular}{|c|c|c|c|c|c|c|c|c|c|c|c|c|}
\hline $\mathrm{S}_{26}$ & $\mathrm{~S}_{27}$ & $\mathrm{~S}_{28}$ & $\mathrm{~S}_{29}$ & $\mathrm{~S}_{30}$ & $\mathrm{~S}_{31}$ & $\mathrm{~S}_{732}$ & $\mathrm{~S}_{33}$ & $\mathrm{~S}_{34}$ & $\mathrm{~S}_{35}$ & $\mathrm{~S}_{36}$ & $\mathrm{~S}_{37}$ & $\mathrm{~S}_{38}$ \\
\hline 0.175 & 0.202 & 0.215 & 0.238 & 0.230 & 0.240 & 0.255 & 0.168 & 0.169 & 0.172 & 0.215 & 0.201 & 0.212 \\
\hline $\mathrm{S}_{39}$ & $\mathrm{~S}_{40}$ & $\mathrm{~S}_{41}$ & $\mathrm{~S}_{42}$ & $\mathrm{~S}_{43}$ & $\mathrm{~S}_{44}$ & $\mathrm{~S}_{45}$ & $\mathrm{~S}_{46}$ & $\mathrm{~S}_{47}$ & $\mathrm{~S}_{48}$ & $\mathrm{~S}_{49}$ & $\mathrm{~S}_{50}$ & -- \\
\hline 0.225 & 0.123 & 0.171 & 0.238 & 0.149 & 0.171 & 0.169 & 0.142 & 0.170 & 0.182 & 0.180 & 0.083 & --- \\
\hline
\end{tabular}

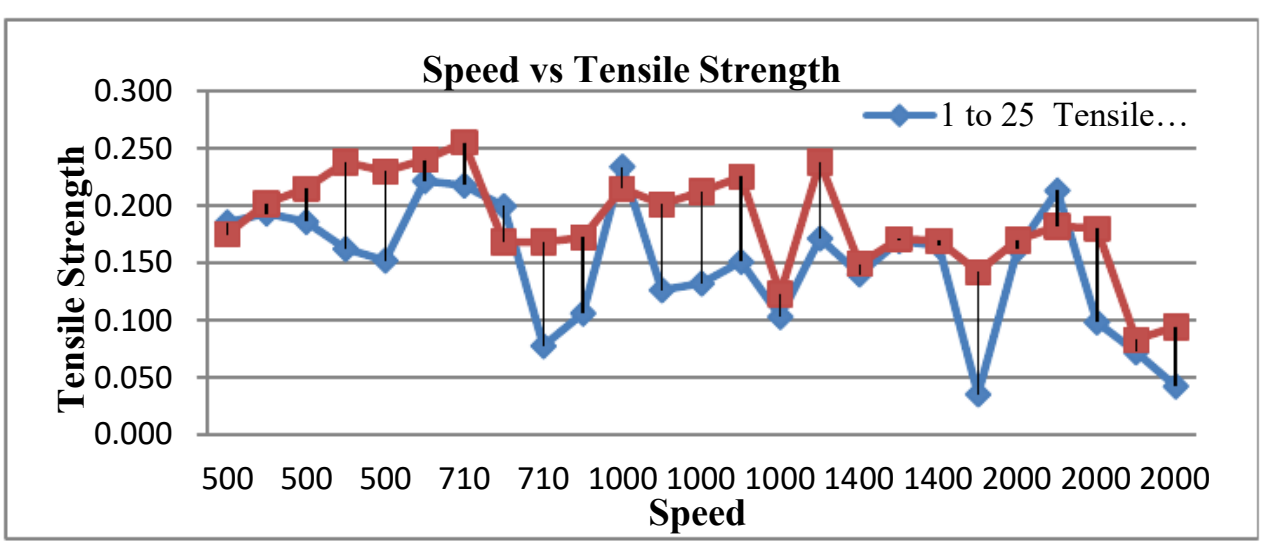

Figure 7. Tensile strength versus speed for both profiles.

\section{CONCLUSIONS}

Experiments were led for different mixes of hardware speed, feed, stick profile, bear infiltration and tilt edge at five dimensions in Taguchi's symmetrical cluster. The quality of the joint was examined by malleable test.

1. Pin profiles with cylindrical and square shapes impacts to produces great quality weld. Of the twenty-five joints, the joints manufactured by square stick profiled device showed better elastic properties looked at than tube shaped device profile.

2. At the point when the welding velocity and feed is quicker than the specific esteem then elasticity continues diminishing.

3. Speed, feed, hub constrain, tilt edge is expanding and bear distance across diminishing at that point welding deserts happens which prompts diminishing in rigidity.

4. Axial force is the vertical descending power connected to dive the work piece in to the weld line. Adequate pivotal power is required to frame the sound weld on the grounds that amid the procedure will control the measure of plasticized material and the temperature is relying upon the hub constrain.

5. Rigidity get from square profile is higher than barrel shaped profile which is $0.255 \mathrm{kN} / \mathrm{mm} 2$.

\section{REFERENCES}

[1] Thomas WM, Nicholas ED, Needham JC, Murch MG, Temple-Smith P, Dawes CJ., Friction stir butt welding, International Patent Application No. PCT/GB92/02203; 1991.

[2] M. Ecomoto, Friction stir Welding: Research and industrial applications, Welding International, 17(3), 2003, pp. 341-345. 
[3] Thomas WM, Friction stir welding - recent developments, Mater Sci. Forum, 2003, 426432:229-36.

[4] R.S. Mishraa, Z.Y. Ma, Friction stir welding and processing, Materials Science and Engineering, R 50, 2005, pp. 1-78.

[5] Singh R. K. R., Sharma C., Dwivedi D. K., Mehta N. K., Kumar P., The microstructure and mechanical properties of friction stir welded $\mathrm{Al}-\mathrm{Zn}-\mathrm{Mg}$ alloy in as welded and heat-treated conditions, Materials and Design,32, 2011, pp. 682-687

[6] G. C. am, Friction stir welded structural materials: beyond Al-alloys, International Materials Reviews,56(1), 2011, pp.1-48.

[7] Indira Rani M, Marpu R.N. and A.C.S. Kumar, A study of process parameters of friction stir welded AA6061 aluminium alloy in o and t-6 conditions, APRN Journal of Engineering and Applied Science Engineering, 6(2), 2011, pp.61-66.

[8] K. Elangovan, V. Balasubramanian, Influences of pin profile and rotational speed of the tool on the formation of friction stir processingzone in AA2219 aluminium alloy, Materials Science and Engineering, A 459, 2007, pp. 7-18.

[9] Z. Barlas and U. Ozsarac Effects of FSW Parameters on Joint Properties of AlMg3 Alloy welding journal january 2012, 91(1), 16s-22s.

[10] Ahmed Khalid Hussain, Sayed Azam Pasha Quadri, Evaluation of parameters of friction stir welding for aluminium AA6351 alloy, International Journal of Engineering Science and Technology,2(10), 2010, pp. 5977-5984.

[11] Phillip J. Ross, Taguchi Techniques for Quality Engineering, McGraw Hill Education (India) Private Limited, New Delhi, Second Edition, 2005, pp.45-73.

[12] P. Janaki Ramuluet al, Internal defect and process parameter analysis during friction stir welding of Al 6061 sheets,Int J AdvManufTechnol 2013, 65, pp.1515-1528 DOI 10.1007/s00170-0124276-Z

[13] Zeng WM, Wu HL, Zhang, J Effect of tool wear on microstructure, mechanical properties and acoustic emission of friction stir welded 6061 Al alloy, ActaMetall Sin, 2006,19(1), pp.9-19.

[14] Oosterkamp A, Djapic Oosterkamp L, Nordeide A, Kissing bond phenomena in solid state welds of Aluminum alloys, Welding Journal, 2004, 8, pp.225s-231s.

[15] Thomas WM, Nicholas ED, Friction stir welding for the transportation industries, Mater Des, 1997, 18, pp.269-273.

[16] Krishnan KN, On the formation of onion rings in friction stir welds, Mater SciEng,2002, A 327, pp.246-251.

[17] Puneet Rohilla, Narinder, Experimental Investigation of Tool Geometry on Mechanical Properties of Friction Stir Welding of AA6061, IJITEE,2013, 3(3), pp.56-61

[18] Arunabh Mani Tripathi, Aakash Sharma, Bharat Bhusan Patra, Prashant Kumar Pandey, Ramesh Chand, and Gopal Rana A Review on Friction Stir Welding of aluminium Alloys: Mechanical Properties and Metallurgical Observations. International Journal of Mechanical Engineering and Technology, 8(7), 2017, pp. 1546-1555.

[19] AakashSharma, Arunabh ManiTripathi, and BrainChoudhary, Prashant Kumar Pandey, Hitesh Arora, and Vishaldeep Singh, A Review on The Friction Stir Welding of The Sheets of Dissimilar Materials. International Journal of Mechanical Engineering and Technology, 8(7), 2017, pp. 1457-1464.

[20] Rahul S G, Kavitha P, Adaptive Controller to Minimize Position Disturbances of Tool Pin While Joining Aluminium Metal Matrix Composites by Friction Stir Welding, International Journal of Mechanical Engineering and Technology 9(10), 2018, pp. 399-416.

[21] G Sarat Raju, B.Balunaik, D.V.Ravi Shankar and Dussa Govardhan, Analysis and Fabrication of Aluminium Alloy Aa6061 Butt Joint Using Friction Stir Welding, International Journal of Mechanical Engineering and Technology 8(10), 2017, pp. 774-783.

[22] P. Jayaseelan and T. V. Christy, Behavior of Threaded Cylinder Tool in the Friction Stir Welding of Al-Zrb2 and Al-Sic Composite, International Journal of Mechanical Engineering and Technology, 10(01), 2019, pp.1751-1761 